\title{
The Work and Lives of Street Waste Pickers in Pretoria-A Case Study of Recycling in South Africa's Urban Informal Economy
}

\author{
Rinie Schenck • Phillip Frederick Blaauw \\ R. Schenck \\ Department of Social Work, University of South Africa (UNISA), P O Box 392, Pretoria 0003, South Africa \\ P. F. Blaauw $(*)$ \\ Department of Economics and Econometrics, University of J ohannesburg, P O Box 524, Auckland Park 2006, \\ South Africa e-mail: pfblaauw@uj.ac.za
}

\begin{abstract}
High levels of unemployment are a permanent feature in the urban areas of many developing countries. South Africa is no exception in this regard. Poverty and hardship caused by unemployment force many participants in the labour market to venture into the urban informal economy in order to survive. The activities of the waste pickers fall within the urban informal economy. In spite of the fact that waste pickers are a common sight in the urban areas of Pretoria and other South African cities, remarkably little is known about them and scant attention is paid to them. The aim of the study was to establish a socio-economic profile of the street waste pickers in Pretoria and to describe the social interaction and relationship dynamics between the waste pickers and their families, each other, the community and buy-back centres. This was done by conducting the first ever empirical study of the street waste pickers in Pretoria. The results revealed that the role of street waste pickers in the broader waste management system is an important public issue that requires urgent attention and appropriate policy responses from policy makers.
\end{abstract}

Keywords Urban informal economy. Recycling. Street waste pickers. Waste management system

\section{Introduction}

Urban areas in developing countries share several common characteristics. High and rising levels of urban unemployment are one of the most visible similarities (Rogerson 1996). Many of the urban unemployed have no other alternative but to venture into the informal economy. Samson (2010a:42) indicated that in 2004 the African National Congress (ANC) noted the existence in South Africa of two economies, operating parallel to each other. In this regard, Samson (2010a:42) quotes the ANC (the ruling party of the day) as follows: "The first is an advanced economy based on skilled labour, which is becoming more globally competitive. The second is a mainly informal, marginalised, unskilled economy populated by the unemployed and those unemployable in the formal sector."

Vast numbers of people survive every day in the urban informal economy in the cities of developing countries. Their activities are varied and consist of both legal and illegal economic actions. Activities such as day labouring, small-scale retailing and waste picking are becoming more frequent in the urban areas of the developing world. The activities of waste pickers fall within the informal sector, which is labour intensive and characterised by limited or no use of technology (Theron 2010). The urban areas of South Africa and its capital, Pretoria, are no exception.

Waste pickers are variously referred to in the literature as reclaimers, waste pickers, garbage pickers, recyclers, scavengers and waste salvagers (Schenck and Blaauw 2010; Chvatal 2010; Samson 2010b). Street waste pickers, pushing their trolleys, are an everyday sight in Pretoria. Waste pickers are small-scale, self- employed agents, characteristically encountered in the urban informal sector (Hayami et al. 2006:42). Theron (2010:1) 
confirms the involvement of waste pickers in the informal economy: "most waste pickers have created their own jobs, and work for themselves: in other words they are self employed". Waste is collected either for their own use or to sell (Samson 2010b) to higher-level traders and/ or buy-back centres.

Medina (1997) indicates that in Third World countries recycling is the consequence of poverty and hardship and that roughly $2 \%$ of the world's population makes a living by collecting, sorting, using and/or selling salvageable material from refuse. In Brazil, it is estimated that up to 100,000 people live by collecting and selling recyclables (Langenhoven and Dyssel 2007:115). Langenhoven and Dyssel (2007) also refer to the South African Yearbook for 2004/2005 which indicates that during that period, roughly 37,000 people in South Africa earned a living from recycling. It is an easy market to enter, as there are no barriers to entry and no qualification, permit or permission is required (Hayami et al. 2006:43; Theron 2010).

Street waste pickers are generally either ignored or looked down on because of the work they do, which is perceived as dirty (Schenck and Blaauw 2010). Nevertheless, these people have found a way of supporting themselves, and at the same time (either consciously or unconsciously), they make an important contribution to environmental sustainability by reducing the amount of waste that goes to landfills and by providing material for recycling processes (Langenhoven and Dyssel 2007; Samson 2010b). Samson (2010b:1) makes the important point that although we observe these people on the street, "remarkably little is known about the reclaimers in South African cities and scant attention is being paid to them."

\section{Aim of the Study}

The aim of the study was to:

Establish a socio-economic profile of the street waste pickers in Pretoria

Describe the social interaction and relationship dynamics between the waste pickers and their families, each other, the community and the buy-back centres.

This article documents the findings of the first empirical study of the street waste pickers in Pretoria. We also describe the daily routine of the people involved in this form of waste collection.

In this study, the term street waste pickers will be used to refer to those people who collect waste on the streets with trolleys. People collecting waste on the dumpsites or landfill sites are not included in the study. Benson and Vanqa-Mgijima (2010) report that in Cape Town the waste pickers referred to their work as "skarreling", "grab grab", "mining" and "minza" (the latter meaning "trying to survive").

\section{Literature Study}

According to Hayami et al. (2006), waste pickers constitute the bottom tier of the urban informal sector. We created the simple figure below to illustrate the position occupied by the waste pickers in the broader waste management system (Fig. 1). 


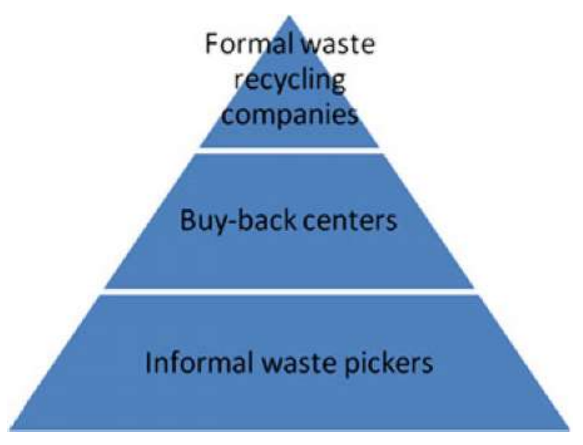

Fig. 1 The position of informal waste pickers in the broader waste management system

In South Africa, the municipal waste management systems do not appear to be ready to accommodate the waste pickers. However, Gerdes and Gunsilius (2010) indicate that the official waste management systems in many cities, such as Cairo, could not be managed without the myriad of waste pickers and scrap collectors, who often form the basis of waste collection services at no cost to local authorities, central government and residents. Gerdes and Gunsilius (2010) further emphasise that while informal activities such as street waste picking very often take place outside official and formal channels and are unlicensed and untaxed, street waste pickers nevertheless contribute significantly to national economies. These authors conclude that street waste pickers "are entrepreneurs who add value merely by collecting and then transforming waste into tradable commodities" (Gerdes and Gunsilius 2010:5; see also Hayami et al. 2006:42). Another advantage of organically grown informal sector activities such as this is that they are highly adaptable and flexible, and able to respond quickly to demand-driven forces (Gerdes and Gunsilius 2010).

The literature review revealed that much has been written about waste pickers working and living on dumpsites or landfill sites in South Africa, but very little about street waste pickers (Chvatal 2010; Samson 2010a). The only research on street waste pickers has been conducted by Schenck and Blaauw (2010) and Benson and Vanqa-Mgijima (2010) in Cape Town, McLean (2000) in Durban and Langenhoven and Dyssel (2007) in Mitchells Plain (Cape Town).

According to Benson and Vanqa-Mgijima (2010:2), South Africa has a long history of people collecting waste off the streets to survive. They suggest that since the adoption of neo-liberal policies in South Africa, the scale of private reclaiming has increased, as has the availability of poor people to take part in the reclaiming chain. One of the reasons for this is increasing levels of unemployment. J ob losses have shifted people onto the streets in order to earn an income or sustain a livelihood, and, as Medina (2007) indicates, waste collecting and selling is an activity that saves many people from starvation (see also Theron 2010).

Waste pickers should further be considered in the context of a formal waste management cycle. There cannot be waste collection if there is no waste generation (Schenck and Blaauw 2010). The waste cycle is illustrated in Fig. 2.

Waste pickers can make a living only if there are people who generate waste. Medina (2007) states that the amount and characteristics of waste generated in First and Third World countries differ markedly. Waste generation rates in industrialised cities are typically higher than in cities in Third World countries, and the quantity of 


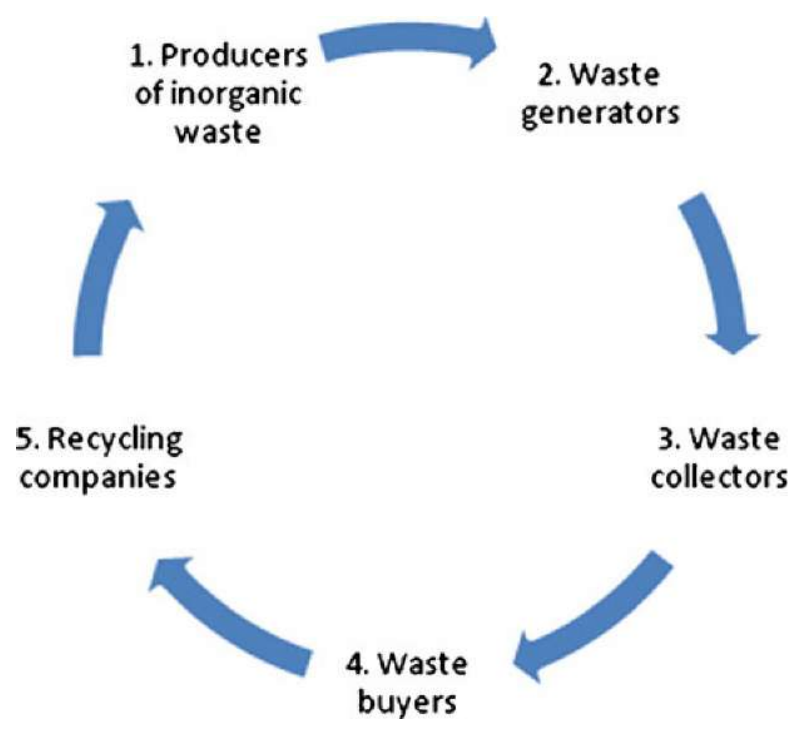

Fig. 2 The waste cycle. Source: Schenck and Blaauw (2010).

waste generated tends to increase as income increases. The average US resident produces over $1.5 \mathrm{~kg}$ of waste per day, while a person in Cotonou, Benin (Africa) produces only $125 \mathrm{~g}$ in the same period. Waste generated by First World communities therefore creates survival opportunities for waste pickers who live in these communities.

Another dimension that sustains the informal waste management system is the existence of buyers or buy-back centres and recycling companies. If there is no waste and nobody to buy and recycle the waste, there would be no reason for the waste pickers to enter this sector. Gerdes and Gunsilius (2010) report that several studies have shown that these informal recycling activities have positive effects on the environment, reduce the costs of waste management systems and provide income opportunities for large numbers of poor people. Dias (2009), who was involved with organizing and researching the street waste pickers in Belo Horizonte, Brazil, confirmed that in 2008, 5,100 tons of waste was collected by informal waste pickers in the streets and the dumpsites. This amounted to $52 \%$ of all the recyclables in Belo Horizonte.

\section{The Research Process and Methodology}

Schenck and Blaauw (2010) identified several important areas in their qualitative study on waste pickers conducted in 2009 requiring further quantification. This shaped the mixed method approach followed in this study, which consisted of a quantitative survey coupled with qualitative questions. Creswell and Plano Clark (2011:5) describe the mixed method approach as a method focussing "on collecting, analysing, and mixing both quantitative and qualitative data in a single study or series of studies. Its single premise is that the use of quantitative and qualitative approaches in combination provides a better understanding of research problems than either approach alone".

Creswell and Plano Clark (2011:61) further state that one of the most important considerations when using the mixed method design is to be explicit in stating the reason for doing so. These authors identify a variety of mixed method research designs (Creswell and Plano Clark 2011:69). Our study followed the multiphase design, which entails combining the concurrent and/ or sequential collection of quantitative and qualitative data sets over multiple phases of a study. This study is part of a more extensive research project, which is illustrated below in Fig. 3.

\section{https://repository.uwc.ac.za/}




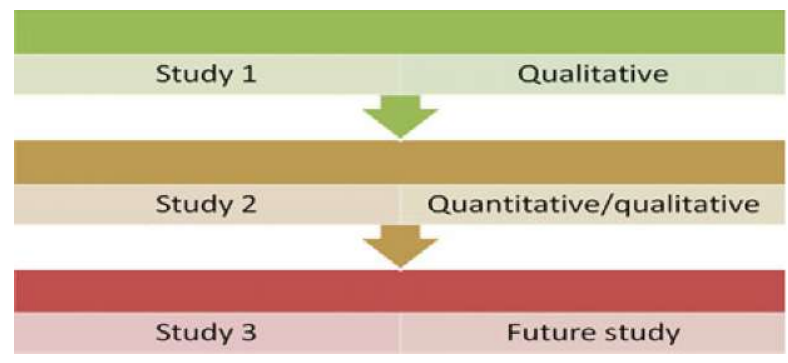

Fig. 3 Multiphase mixed method research. Source: Creswell and Plano Clark (2011:69)

The long-term aim of the study is to compile a profile of the street waste pickers in South Africa, as they constitute a largely unresearched phenomenon. The research followed the process set out below:

Study 1: Qualitative Study (2009)

In 2009, with the assistance of five fourth-year level student social workers in the Department of Social Work at Unisa, in 2009 we undertook a qualitative study of street waste pickers in order to obtain a basic understanding of the activities and lives of this group of people (Schenck and Blaauw 2010). According to Creswell and Plano Clark (2011:40), the first qualitative phase in the multiphase design is usually constructivist, in that: "The understanding or meaning of phenomena, formed through participants and their subjective views, make up this worldview." In this form of inquiry, research is shaped from the bottom up by listening to the voices of the people; from individual perspectives, broad patterns then emerge (Schenck and Blaauw 2010).

Study 2: Quantitative/ Qualitative Study (2010)

Study 2 (the subject of this article) was informed by study 1 . The questionnaire used was developed on the basis of the themes and patterns emerging from the results of the qualitative study (study 1). Some qualitative questions were built into the questionnaire to clarify a number of the quantitative items. Creswell and Plano Clark (2011:40) are of the opinion that this approach includes both post-positivist and constructivist thinking to allow the participants to give their own meaning to some of the questions.

The results of study 2 will offer insight into how to extend research on this subject to the cities and towns in the rest of South Africa so as to arrive at a more nuanced picture of the socio-economic situation of the street waste pickers in South Africa. This will constitute the third study, as illustrated in Fig. 3.

As indicated, a questionnaire was compiled on the basis of the qualitative study by Schenck and Blaauw (2010). The questionnaire was tested, revised and completed by a single fieldworker, fluent in a number of the official South African languages, who was able to translate the questionnaire to facilitate respondents' understanding of the questions. This was important, as low literacy levels prevented many respondents from completing the questionnaires without assistance (Creswell and Plano Clark 2011:14). The field worker was experienced, having also assisted us with a national study on day labourers in South Africa (Harmse et al. 2009).

On the basis of initial observations, it was estimated that there were between 150 and 200 street waste pickers active within the Pretoria city limits. The street waste pickers move from one location to another frequently. As a result of this unique behaviour of the research

\section{https://repository.uwc.ac.za/}


population, availability sampling was used in the study and the fieldworker was instructed to interview all the street waste pickers t she could find. Over a 5-week period, she identified and interviewed waste pickers until no new interviewees could be found and information was saturated. In all, 142 respondents were interviewed from July to September 2010, but it is possible that not all the waste pickers in Pretoria were included in the study. Only a couple waste pickers refused to be interviewed.

From the previous study and the testing of the questionnaire, it was evident that the best places to find the waste pickers ware at the buy-back centres, where they sell the goods they have collected. The buy-back centres identified in Pretoria belonged to only two companies which, for reasons of confidentiality and ethics, are designated as companies $\mathrm{M}$ and $\mathrm{N}$. The waste pickers on the streets directed the fieldworker to the buy-back centres. The fieldworker noted that she encountered the same waste pickers at different buy-back centres. She inferred that they would, for instance, deliver goods to a depot in a particular area on 1 day, and on the next would make their way to another buy-back centre. The study of street waste pickers in India conducted by Hayami et al. (2006) reveals similar movements between buy-back centres.

In the next section, the results of the study will be discussed and linked with the relevant literature. In this study, in order to make valid comparisons, we consulted literature on street waste pickers only.

\section{Results of the Study}

Section A: Demographic Profile of the Street Waste Pickers in Pretoria

In this section, we present the demographic profile of the waste pickers in Pretoria.

\section{Race and Gender of the Participants}

The majority of street waste pickers in Pretoria was male (97.2\%) and all were black. This bears out the findings of Benson and Vanqa-Mgijima (2010) in Cape Town, although the street waste pickers in some of the areas included in their study included coloured people. In the micro-study of 20 waste pickers conducted by McLean (2000) in Durban, 15 (75\%) were male and five (25\%) were female; all were black. Hayami et al. (2006) reported that in Delhi, India, the respondents were all male; but that in other cities, the respondents included more females. Less than 3\% of the street waste pickers in Pretoria was female. It is possible that more women might be found at the landfill sites, as they may find trolleys too heavy to move and would possibly be more vulnerable to the elements and crime (Chvatal 2010; Samson 2010a). The women interviewed in Pretoria were either in a relationship with men or were office workers who took waste paper to the buy-back centres to earn additional income.

\section{Language Spoken by the Participants}

The largest groups of street waste pickers spoke Sepedi (43\%), isiNdebele (20\%), Xitsonga (14\%) and isiZulu (11\%), respectively (Fig. 4). We expected the waste pickers to include people who spoke Sepedi and isiNdebele, as these are the languages spoken by the people who traditionally live close to Pretoria. The small number of Setswana-speaking people (2\%) was surprising, as this language is spoken by another group which traditionally lives close to Pretoria. Xitsonga-speaking people come from a remote rural area roughly $500 \mathrm{~km}$ from Pretoria. Seven percent of the waste pickers indicated that they spoke Tshivenda, while isiXhosa, siSwati and Sesotho were spoken by $1 \%$ each (=3\%).

\section{https://repository.uwc.ac.za/}


Fig. 4 Distribution (percentages) of languages spoken by street waste pickers in Pretoria, Gauteng 2010 (percentages). Source: Survey data

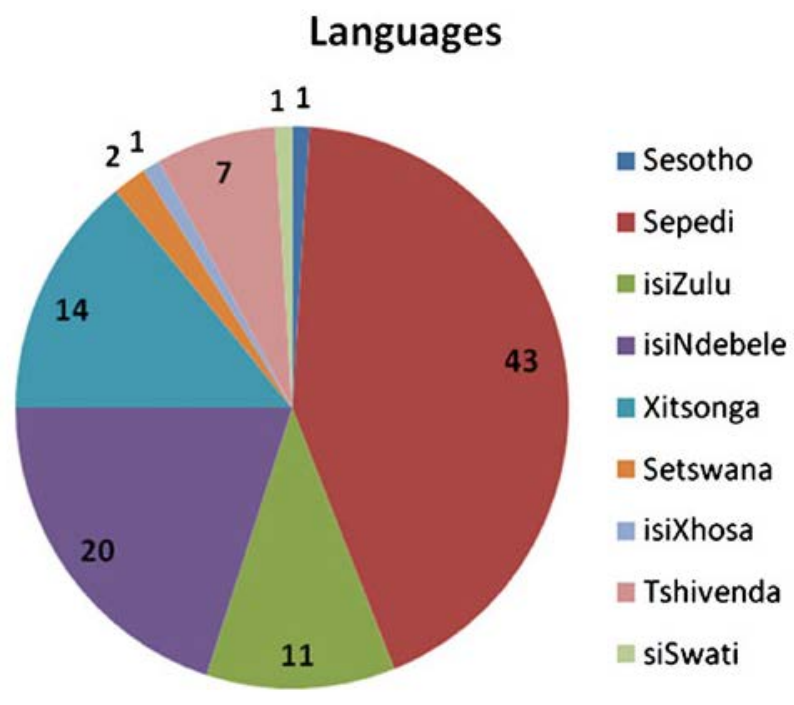

Fig. 4 Distribution (percentages) of languages spoken by street waste pickers in Pretoria, Gauteng 2010 (percentages). Source: Survey data

\section{Province of Birth of Waste Pickers}

Information supplied by respondents indicates that they were born in South Africa, but were migrants from the rural areas and other provinces. This is illustrated in Fig. 5 below. Only 3\% of the respondents was born in the province of Gauteng (Fig. 5). The vast majority, $63 \%$, was born in Limpopo. A further 20\% and 9\% were born in Mpumalanga and KwaZulu-Natal, respectively. The remaining $4 \%$ was from the Eastern Cape, Free State and North West. None of the waste pickers were born in the Western Cape or the Northern Cape. This correlates well with the languages spoken by the respondents, as shown in Fig. 4. Hayami et al. (2006) indicate that in Delhi 89\% of the waste pickers who participated in the study originated in the rural areas and migrated to the city, as

Fig. 5 Province of birth of street waste pickers in Pretoria, Gauteng, 2010. Source: Survey data

\section{Province of birth}

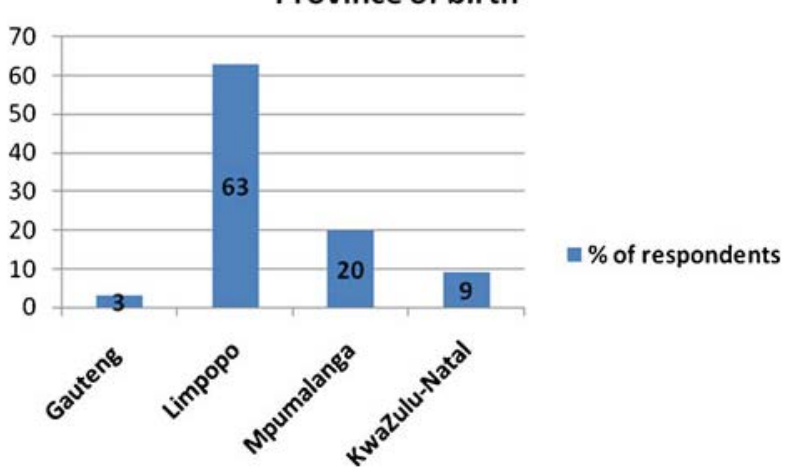

Fig. 5 Province of birth of street waste pickers in Pretoria, Gauteng, 2010. Source: Survey data

waste picking is an occupation that new migrants from rural areas are able to engage in fairly easily. The presence of a few foreigners among the waste pickers in Cape Town was noted, but no foreigners were interviewed in the Pretoria study.

\section{https://repository.uwc.ac.za/}




\section{Age Distribution of the Street Waste Pickers}

The age distribution of the waste pickers is illustrated in Fig. 6.

The majority of the street waste pickers (49\%) was between the ages of 41 and 50 . Only one respondent was below the age of 25 and was 20 years old. Only $6 \%$ was above the age of 56 and the eldest 60. The ages of participants in the Cape Town study ranged from 30 to 80 (Benson and Vanqa-Mgijima 2010); and in the Durban study (McLean 2000), the ages ranged from 23 to 72 , the average age being 45 . The studies by Schenck and Blaauw (2010) and Samson (2010b) also revealed the majority of participants to be between the ages of 40 and 50. The street waste pickers differed considerably in age from day labourers (men who stand on the side of the road seeking day labour opportunities), who were generally much younger, the majority tending to be between 20 and 30 years of age (Blaauw 2010). It seems as if waste picking is more physically appropriate and manageable to older people than day labour work which requires standing long hours next to the road as well as hard physical labour. Furthermore, day labouring serves as an entrance point for a significant number of immigrants from South Africa's neighbouring countries, seeking to improve their material circumstances. These immigrants tend to be younger (Blaauw 2010).

Langenhoven and Dyssel (2007) indicate that 45\% of the group interviewed in Mitchells Plain (Cape Town) was between 50 and 65 years of age. Most of the waste pickers indicated that they would have preferred full-time employment, but that employment opportunities for people above 40 years of age were very scarce if they had no work experience in the formal economy. Although most of the waste pickers in the Pretoria study indicated that they had previously had a full-time job, these were mainly temporary, short-term menial jobs as farm workers, petrol attendants and assistants to builders and painters and so on. Their predicament was compounded by their low levels of schooling, discussed in the next section.

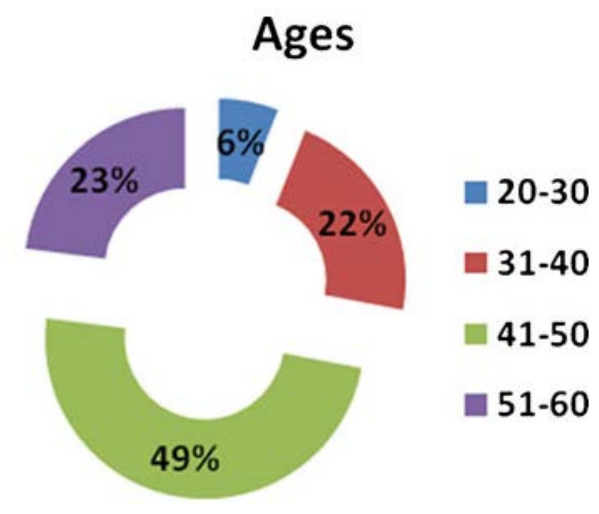

Fig. 6 Age distribution of street waste pickers in Pretoria, 2010. Source: Survey data

\section{Schooling}

Figure 7 shows the highest school grade completed by the respondents.

The survey data revealed the very low level of schooling of the waste pickers interviewed; this probably constituted one of the main reasons for their inability to obtain full-time employment.

In answering the qualitative question as to why they left school, most of the respondents cited "poverty" or "lack of money" as the main reasons. Some could not afford school 
uniforms, and some were living on farms and could not reach a school, or the school they attended offered only primary school education. "Had to look after the cattle" and "being a herd boy" were also mentioned as reasons by waste pickers originating from rural areas. Of interest was the fact that none of the respondents had had no schooling at all.

Low levels of schooling also emerged from the qualitative study by Schenck and Blaauw (2010), while Hayami et al. (2006) reported that $90 \%$ of the participants in their study was illiterate. The highest qualification completed by any of their respondents was Grade 8. Samson (2010b) confirms that in the studies she summarised, most waste pickers had some primary school education.

\section{Section B: Waste Pickers' Activities}

In this section, we describe the daily lives of waste pickers on the streets of Pretoria and their collection activities.

\section{Length of Time Spent as a Waste Picker}

The majority of the Pretoria waste pickers appeared to have entered waste picking fairly recently. One respondent indicated that he had been a waste picker since 1998 (12 years), while $90 \%$ had become waste pickers during the previous 5 years.

These findings correspond with those of studies conducted in other parts of the country. McLean (2000) found that in Durban, 55\% of the collectors had been in the collection business for less than 2 years, while Langenhoven and Dyssel (2007) indicated that only $35 \%$ of the collectors in Mitchells Plain had engaged in this activity for 10 years and more. There is, of course, always an exception to the general trend. In Cape Town, a waste picker who participated in the study by Benson and Vanqa-Mgijima (2010) indicated that he had been engaged in waste picking for approximately 20 years,

\begin{tabular}{|l|l|l|l|l|l|l|l|l|l|}
\hline Gr3 & Gr4 & Gr5 & Gr6 & Gr7 & Gr8 & Gr9 & Gr10 & Gr11 & Gr12 \\
\hline $13 \%$ & $15 \%$ & $18 \%$ & $17 \%$ & $13 \%$ & $10 \%$ & $8 \%$ & $2 \%$ & $3 \%$ & $1 \%$ \\
\hline
\end{tabular}

Fig. 7 The highest level of schooling completed by street waste pickers in Pretoria, 2010. Source: Survey data

having discovered after he lost his job that he could make money from collecting waste. Still engaged in waste picking, he regarded it as "work" or a "business", and not merely a temporary source of income.

Activities Involved in Street Waste Collecting

The Pretoria street waste pickers surveyed reported that on entering the "business" of collecting waste on the street, a waste picker's first action would be to obtain a trolley as soon as possible. The picker would find a friend willing to share a trolley or would use boxes

\section{https://repository.uwc.ac.za/}


until he or she was in a position to buy, make or steal a trolley. Waste pickers would often carry these boxes on their heads until they could afford a trolley (also see McLean 2000). Some admitted to having stolen a trolley from a supermarket parking area. Figure 8 illustrates some of the modifications made to their trolleys by the street waste pickers.

Two of the women, who worked in offices close to a buy-back centre, collected waste paper in bins, and took it to the buy-back centre. In her Durban study, McLean (2000) ascertained that waste pickers collecting goods with a trolley earned more because they were able to move faster and consequently collect more effectively.

\section{Items Collected}

What the waste pickers collect is determined by what they can sell and/ or use. The research revealed that the buy-back centres buy paper, cardboard boxes, plastic bottles and in some instances, scrap metal. On waste collection days, the waste pickers search through dustbins and remove "valuable" items such as these before the dustbins are emptied by the municipality. The waste pickers also collect "valuables" for themselves, such as clothing, food and electronic devices such as cell phones for personal use, to sell and to "give away as gifts" (also see McLean 2000:18). Samson (2010b) found that waste pickers on landfill sites also collected pots and pans, blankets and detergent-in short, anything they can use in their own homes.

The goods collected by the street waste pickers in this study were sold at fixed prices as determined by the two companies. There was a significant difference

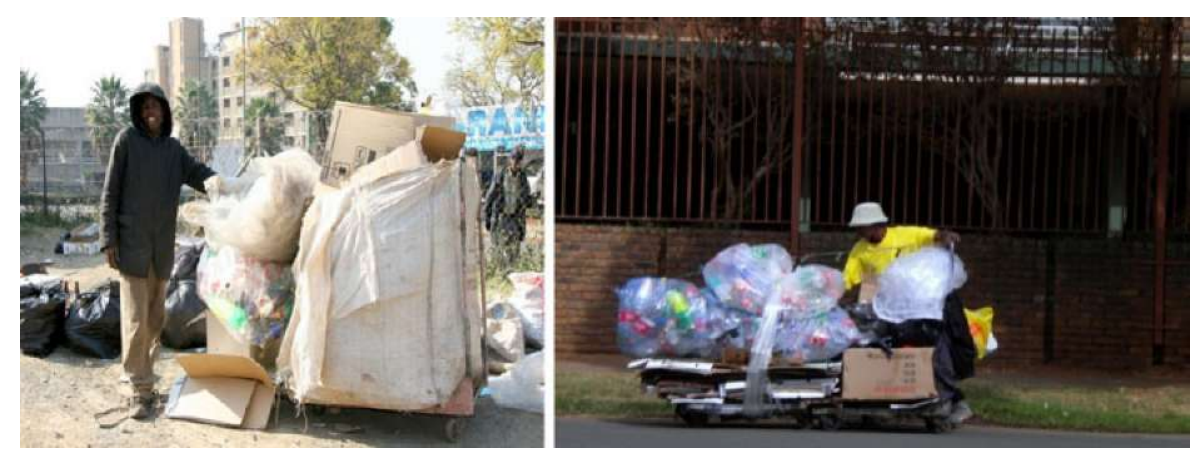

Fig. 8 Some street waste pickers with their modified trolleys

between the prices paid: company $\mathrm{M}$ bought the goods for literally half the price paid by company N. Company M offered between 35c and 50c per kilogramme for boxes, compared with the 70c per kilogramme offered by company $\mathrm{N}$. Company $\mathrm{M}$ offered R1 per kilogramme for white paper, compared with the R1.70 to R2 offered by company N. The reasons for the differences in the various prices offered to the street waste pickers merit further research.

\section{Daily Collection Pattern}

The participants in the survey all indicated they had a routine, beginning early in the morning. Most indicted that they began collecting between 06:00 and 08:00 hours, and delivered any time between 10:00 and 15:00 hours. Some stated that they continued collecting until 18:00 hours. After delivering what they had collected, most respondents would rest, eat, drink and socialise. Some began working again later to collect for the following day's delivery.

\section{https://repository.uwc.ac.za/}




\section{Living on the Streets}

Figure 9 provides an indication of the various places where the street waste pickers in Pretoria slept at night.

The data indicates that only $4 \%$ of the respondents slept at home, while the rest (96\%) slept elsewhere: this included backyard rooms (4\%), in the veld or under bushes (15\%), "on the street" (69\%), backyard shacks (4\%), men's hostels in the townships (4\%) and deserted houses.

It was interesting to note that respondents answered the quantitative question by saying that they slept on the street, and when asked to qualify the answer, they stated that they slept "where it is safe". In this case, "safe" implied sleeping in groups for protection, as this made them less vulnerable to crime.

This trend, too, is supported by the findings of other studies. Benson and Vanqa-Mgijima (2010) corroborated that in Cape Town most of the street waste pickers lived and slept "on the streets", with some sleeping in the townships around Cape Town. McLean (2000) reported that $85 \%$ of the waste pickers surveyed in Durban came from rural KwaZulu-Natal, but lived on the streets of Durban close to the buy-back centres.

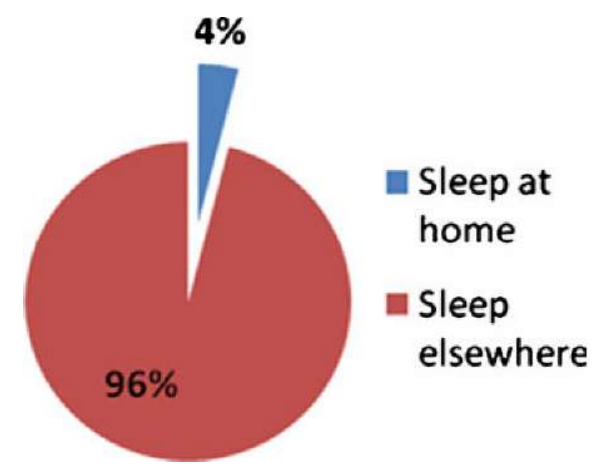

Fig. 9 Places where the street waste pickers sleep, Pretoria 2010. Source: Survey data

Living on the street means little access to amenities such as water, toilets and washing facilities, and this seems to be one of the most significant difficulties experienced by the respondents. The waste pickers living in the street or in the open veld (96\%) went to filling stations and shops and used streams for water and toilet facilities and to wash themselves and their clothes. Some of the buy-back centres made some facilities available for the waste pickers.

The respondents in this study further explained that they either cooked for themselves where they slept on the street or in the veld, or bought food at the shops. Quite a number (36\%) indicated that they also regularly received food from churches. Dustbins put out by residential homes and restaurants were also a source of food. No assistance or support in this regard was offered by the government, local government or NGOs.

\section{Working Conditions}


The waste pickers described their working conditions as harsh as they are exposed to the elements. The trolleys are heavy to push over long distances. When asked whether they experience any work-related injuries, most answered in the negative. The only significant danger they faced was being run over by cars at intersections. Given that they collect mainly paper and plastic bottles, potential injuries would probably take the form of cuts. Surprisingly, the Pretoria waste pickers did not cite crime as one of their greatest concerns. In this, they differed from the waste pickers of Mitchells Plain surveyed by Langenhoven and Dyssel (2007). These waste pickers experienced theft as an important stumbling block in their day to day activities.

Some potential problems were more significant in some regions than others. Langenhoven and Dyssel (2007) and McLean (2000) mentioned the weather as a significant problem for the waste collectors in Cape Town and Durban, respectively, as inclement weather made collection difficult, and the buy-back centres pay less if the paper or cardboard boxes are damp. McLean (2000) noted that the Durban waste pickers did not experience many problems, but that those experienced were serious in nature, such as theft, and the lack of accommodation and access to basic facilities.

\section{Section C: Relationships}

The relationships between street waste pickers and their families, buy-back centres, other waste pickers and the community are complex owing to the distance from their families on the one hand, and the relatively "close" interaction with the other three groups on the other. This interdependence is illustrated in Fig. 10.

\section{Waste Pickers' Relationships with Their Families}

The study revealed that the respondents appeared to have little or no physical contact with and support from their families. Hayami et al. (2006:48) found that almost all the waste pickers in Delhi received family support, whereas in Pretoria the large majority of the street waste pickers operated at a distance from their families, with only $4 \%$ sleeping at home.

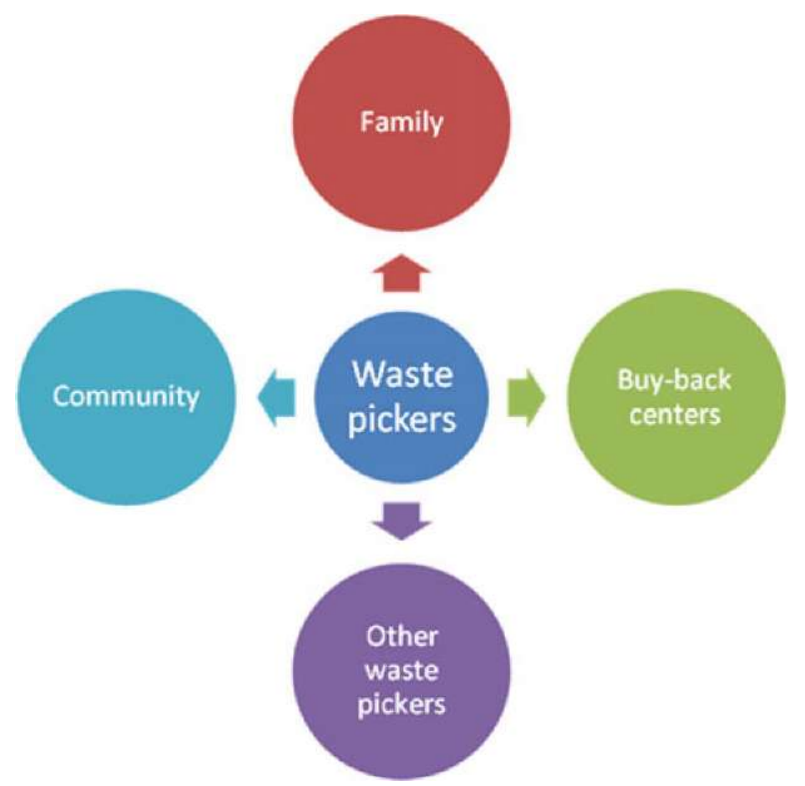

Fig. 10 Relationships between street waste pickers and other social groupings

\section{https://repository.uwc.ac.za/}


The table below indicates the marital status of the respondents (Table 1). Less than half of the respondents (47\%) were married. The rest were unmarried (33\%), separated or divorced (18\%) or widowed (2\%). In total, 53\% was unmarried. Given that they have to scratch out a living simply to sustain themselves, it is not surprising that so many are not married. In the qualitative study by Schenck and Blaauw (2010), too, the respondents who classified themselves as single outnumbered those who were married or in a relationship. The fieldworker also observed the disconnectedness between the waste pickers and their families. This unfortunate state of affairs was also confirmed when the respondents were asked to indicate how often they visited their families.

\section{Frequency of Visits to Family}

Figure 11 illustrates the answers of the respondents to this question.

It emerged from the data that $84 \%$ of the respondents saw their families only twice a year or less. Only 3\% saw their families daily, $1 \%$ weekly, $6 \%$ monthly and

\begin{tabular}{llc} 
Table 1 Marital status of street & & Percent \\
\cline { 2 - 3 } waste pickers in Pretoria, 2010 & Marital status & 33 \\
\cline { 2 - 3 } & Never married & 18 \\
& Separated/Divorced & 47 \\
& Married & 2 \\
Source: Survey data & Widowed & 100
\end{tabular}

Table 1 Marital status of street waste pickers in Pretoria, 2010

Fig. 11 Frequency of visits to their families by street waste pickers in Pretoria, 2010. Source: Survey data

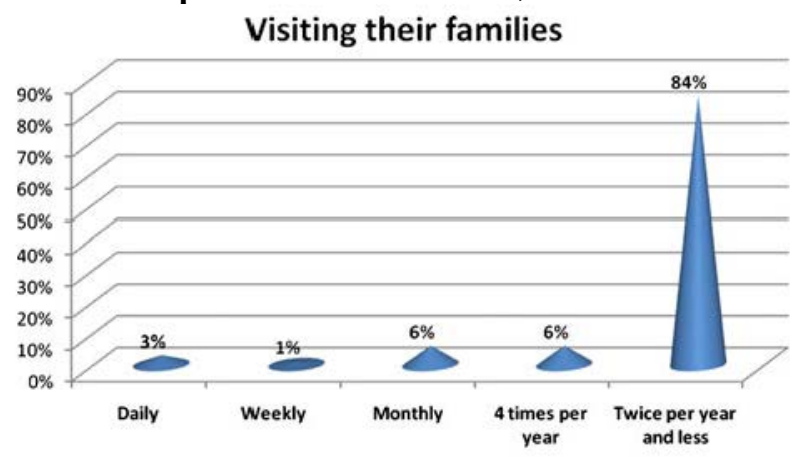

Source: Survey data

Fig. 11 Frequency of visits to their families by street waste pickers in Pretoria, 2010. Source: Survey data

another 6\% quarterly. The collectors participating in McLean's study (2000) indicated that they returned home only if and when they could afford to do so. A similar pattern is followed by others engaging in informal activities: day labourers also maintain that they only visit their families if they have the monetary resources to do so (Blaauw 2010).

These observations are very important when considered in conjunction with the areas where the street waste pickers' families live. This is shown in Fig. 12 below.

Most of the respondents' families (57\%) lived in Limpopo. Nineteen percent lived in Mpumalanga. Only 4\% lived in North West, which is interesting, as North West is one of the closest provinces to Pretoria. Five percent of the respondents indicated that they had "no

\section{https://repository.uwc.ac.za/}


family". Four of the participants indicated that they had families/ dependants in more than one province.

Given the distances involved, it is understandable that if the waste pickers do not earn enough, they are not able to visit their families regularly. As a result, family ties could be weakened or severed altogether.

\section{Financial Support to Families at Home}

We expected to find that waste pickers collect and sell recyclable items to support themselves and their families. However, it emerged that mostly they earn so little that they are unlikely to be able to contribute to the support of their families.

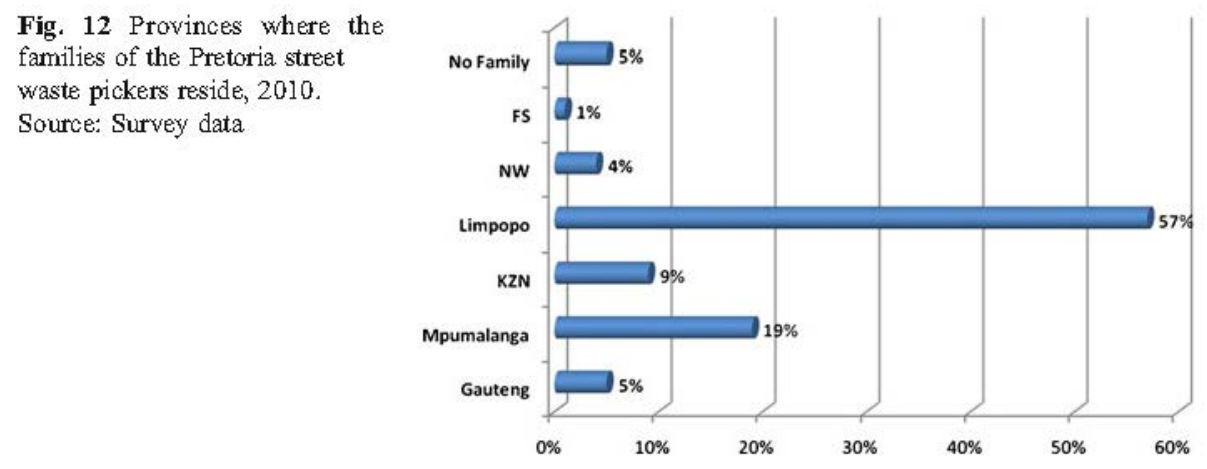

Fig. 12 Provinces where the families of the Pretoria street waste pickers reside, 2010. Source: Survey data

The income earned by the street waste pickers was not only low, but also varied significantly, as shown by the data. Respondents were asked to indicate both the lowest and highest daily income that they have earned in the month preceding the interview. The data obtained were used to calculate the average of both these variables. The average lowest income per day earned by waste pickers was R19.15, and the average highest income was R96.78 per day, almost five times as much. However, the highest daily income was the exception rather than the rule. The average weekly income earned by street waste pickers in the week before the interview was R156.35. This provides a more balanced view of the ability of the Pretoria street waste pickers to support themselves and/ or their families.

During the qualitative study by Schenck and Blaauw (2010), the fieldworkers investigated whether the waste pickers had children or dependants, but it was not clear from the feedback whether the concepts "children" and "dependant" were always correctly interpreted by the respondents in that exploratory study. The fieldworker in this study took the time to explain these concepts clearly and was therefore able to obtain a more reliable estimate of the number of people for who the waste pickers were responsible.

Fourteen percent of the respondents indicated that they had only themselves to care for, while $1 \%$ had nine people dependent on their income. On average, four people depend on each waste picker for survival. Similar findings were made by McLean (2000), as the 20 Durban collectors interviewed also supported an average of four persons per waste picker. Irrespective of the poverty line used, it is quite clear that the average street waste picker would find it very difficult to support four people on an average monthly income of R620, particularly as in the event of ill health no income is earned. The situation in other parts of South Africa is quite similar, although the literature suggests that the typical waste picker in 
Cape Town and Durban earns up to 25\% more than in Pretoria. This observation must, however, be viewed with caution as different survey methods were used and calculations will differ.

Benson and Vanqa-Mgijima (2010) reported that some of the waste pickers in Cape Town claimed to earn R60 to R70 per day, while others put their daily earnings at R10 to R50. Daily earnings in Cape Town therefore ranged from R10 to R70. McLean reported that in 2000 the collectors in Durban earned R30 to R60 per day. She postulated that a good collector, working 7 days a week and collecting four commodities, would have been able to earn R840 monthly. Langenhoven and Dyssel (2007) found that in Mitchells Plain the waste pickers earned between R80 and R100 per week, meaning that they also earned up to R400 per month.

McLean (2000) noted the vulnerability of the waste pickers in her study, and the conditions of extreme poverty in which they lived. They had no visible assets except a trolley and the clothes they wore, which were in poor condition. They were unable to afford accommodation and could barely afford food, let alone support a family. This research also revealed that the Pretoria waste pickers were subject to similar conditions.

\section{How Often Street Waste Pickers Send Money Home}

It was disturbing to discover that although on average four people are dependent on the income of each waste picker; only $9 \%$ of the respondents was able to send or take money home daily, weekly or even monthly. Twenty-three percent of the waste pickers was able to send money to their dependants four times per year, $23 \%$ twice per year and $9 \%$ only once a year. Thirty-six percent said they did not earn enough to send any money at all. Although they indicated that they needed to take care of a number of people, they were not able to do so, barely earning enough to sustain themselves daily. Contributions to family support were therefore minimal. The fieldworker noted that some of the buy-back centre managers indicated that some of the waste pickers collected and sold just enough to buy alcohol for the day. Benson and Vanqa-Mgijima (2010) reported waste pickers as stating that they collected to "buy bread and dop" (buy bread and alcohol).

\section{Other Relationships}

\section{Relationships with Other Waste Pickers/ Co-workers}

The disconnectedness of the street waste pickers in Pretoria from their families was mirrored in their relationships with other waste pickers or co-workers. Although they indicated that they might share a trolley on starting out as a waste picker, only $4 \%$ of the waste pickers interviewed indicated that they worked collaboratively. Only 3\% assisted one another in collecting waste, and 1\% might assist other waste pickers financially. Three percent shared food and a place to sleep. It would appear that despite sleeping in groups for security and safety reasons, each one worked individually. In the Cape Town study, it was found that female waste pickers who were romantically involved with their male counterparts would work together with them (Benson and Vanqa-Mgijima 2010). One of the female waste pickers in Pretoria was in a relationship with one of the men, and they, too, worked together. In this regard the waste pickers differed from day labourers, who were found to share their income, food and access to work (Blaauw 2010). In the case of the waste pickers, McLean (2000) confirms the "first come first serve" basis followed by the waste pickers. They have the opportunity to each collect an amount of waste and make a living on their own. Day labourers, on the other hand, tend to share their limited job opportunities and other resources.

\section{https://repository.uwc.ac.za/}


In their Cape Town study, Benson and Vanqa-Mgijima (2010) found that half the participants would work alone, and half would work together. They also reported that some of the waste pickers believed that when you work "you work on your own". They would sometimes help another waste picker if that person was ill and could not work.

\section{Relationship with the Buy-Back Centres}

Langenhoven and Dyssel (2007:126) characterise the relationship between the buy-back centres and the collectors as symbiotic: the more collectors supplying the buy-back centre, the better business is. Most of the collectors in Pretoria reported being treated well by the buy-back centres, indicative of the realisation by these centres that the collectors are an asset to them. Some waste pickers reported being exploited, but most indicated a fairly good relationship of interdependence. The fieldworker noted that some buy-back centres made negative remarks about the waste pickers, but that others were very supportive towards them. In one instance, a staff member at a buy-back centre who received the goods acted as a "bank" for the waste pickers, keeping their money safe to reduce the risk of their being robbed.

\section{Relationship with the Public/Community}

The public's perceptions of the waste pickers were amongst the important themes that emerged during the study. The waste pickers described the public's response towards them as "scornful" to "indifferent" to "sympathetic" and "they give us food and money". No real interactions other than with church-run feeding schemes could be determined. This is evidence of another relationship of disconnectedness.

Interactions with the police and metro police in Pretoria were not indicated as problematic, and the waste pickers appeared in the main to be left alone to do their "job".

\section{Conclusions and Recommendations}

The study conducted among the street waste pickers in Pretoria revealed them to be unskilled, to have a low level of education and to fall outside the formal employment sector. Their work is labour intensive, and, according to the respondents in this study, with the number of collectors on the increase, the market is becoming competitive.

Most were between the ages of 40 and 49, but there is little to prevent people of any age entering this "market" in the informal economy. The Pretoria street waste pickers earned, on average, R50 per day. It is therefore evident that waste pickers do not earn enough to support a family, but engage in this work in order to survive and sustain themselves. As Blaauw (2010:200) notes in his study on the day labourers in South Africa "there is no economic rationale for participation in this activity: it is merely a survival strategy for those involved in it".

It is disturbing to observe that because this means of earning a living does not enable the waste pickers to support their dependants, it does little to strengthen family ties, as most of the waste pickers' families live in the remote rural areas. Most waste pickers were observed as working independently, but they stayed together at night, sleeping in groups on the streets of the city as a measure of protection against criminal activities.

Authors such as McLean (2000), Samson (2010a, b) and Langenhoven and Dyssel (2007) have noted that the waste pickers do not enter the market for the environmental benefit 
their activities may have, but for economic reasons. However, they contribute to environmental sustainability by diverting waste from landfill sites (Samson 2010b). The presence of the waste pickers on the streets of Pretoria may nevertheless have a detrimental effect on the environment: they are forced to make use of the goodwill of the buy-back centres and filling stations for basic facilities such as water and toilets, and if these are not available, open spaces and natural resources are used. As most of the street waste pickers are from the rural areas, they sleep and live on the streets, and in the bushes and along the rivers. They sleep and cook on the pavements, as they have no other facilities. The lack of facilities for both the street waste pickers and day labourers (see Blaauw 2010) creates another environmental problem and is a public issue.

The current literature (e.g. Dias 2009; Samson 2010a, b; Theron 2010) proposes a variety of options, including organizing waste pickers so as to allow them greater representation, including their needs in policies, recognizing them as part of the waste management system of the cities and also acknowledging their contribution to the environment. All of these proposals have merit.

Webster (2010) argues that the waste pickers in a city are not a "personal problem" but a "public issue". They are indeed a public issue that warrants attention and should not merely be ignored by professionals when so many people are unemployed and try to make a living informally. The fact that so many people are homeless in the city, sleep on the streets, have no facilities, earn a living from the waste generated by other citizens and use the open veld and natural resources for their basic physical needs makes this indeed a public issue in every sense.

If local government, recycling companies and NGOs were to consider acknowledging the waste pickers as a valuable link in the waste management chain, they could contribute to a solution by collaborating to improve the situation of these people, to the benefit of both the waste pickers themselves and the general public. This could take the form of the provision of basic amenities such as water for consumption, personal hygiene and washing clothes, toilets and shelters. Recycling opportunities could be expanded through the establishment of more buy-back centres able to accommodate a greater variety of recyclable goods; this would broaden the waste pickers' income base and divert more waste from the landfill sites. This could be part of an enhanced recycling awareness initiative among the greater Pretoria public.

Any policy response requires detailed information. The results of this research indicate the need for further study of waste pickers in other urban areas throughout the country, which would provide an even more detailed picture of the socioeconomic circumstances in which these people live and work, and would reveal possible regional differences in their situation. This information can be used to develop support services for waste pickers in the different regions according to the specific needs of that area and in accordance with the view that they indeed constitute valuable members of the community because of the contribution they make to the urban informal economy of the country.

Acknowledgements The authors are extremely grateful for the valuable comments made by Dr. Alet Harmse, Dr. Margaret O'Neil and the anonymous referee(s) on the earlier drafts of the article. The usual disclaimer applies. 


\section{References}

Benson, K., \&Vanqa-Mgijima, N. (2010). Organising on the streets: a study of reclaimers in the streets of Cape Town. http://www.inclusivecities.org/toolbox/Organizing on the Streets web.pdf. Accessed 15 September 2010.

Blaauw, P.F. (2010). The socio-economic aspects of day labouring in South Africa. Unpublished DCom thesis, Department of Economics and Econometrics, University of J ohannesburg, South Africa

Chvatal, J . (2010). A study of waste management policy implications for landfill waste salvagers in the Western Cape. Unpublished MA dissertation, University of Cape Town.

Creswell, J. W., \& Plano Clark, V. L. P. (2011). Designing and conducting mixed methods research (2nd ed.). Thousand Oaks: Sage

Dias, S. M. (2009). Trajectories and memories-waste \& citizenship forums: unique experiments of social justice and participatory governance. English abstract from unpublished $\mathrm{PhD}$ thesis, Federal University of Minas Gerais State, Belo Horizonte, Brazil.

Gerdes, P., \& Gunsilius, E. (2010). The waste experts: enabling conditions for informal sector integration in solid waste management. http:// www2.gtz.de/ dokumente/ bib-2010/ gtz2010-0137en-informal-sector-

solid-waste-management.pdf. Accessed 10 February 2011.

Harmse, A., Blaauw, P. F., \& Schenck, R. (2009). Day labourers, unemployment and socio-economic development in South Africa. Urban Forum, 20(4), 363-377.

Hayami, Y., Dikshit, A. K., \& Mishra, S. N. (2006). Waste pickers and collectors in Delhi: poverty and environment in an urban informal sector. Journal of Development Studies, 42(1), 41-69.

Langenhoven, B., \& Dyssel, M. (2007). The recycling industry and subsistence waste collectors: a case study of Mitchells Plain. Urban Forum, 18(1), 114-132.

McLean, M. (2000). Informal collection: a matter of survival amongst the urban vulnerable. Africanus, 30 (2), 8-26.

Medina, M. (1997). Informal recycling and collection of solid wastes in developing countries: issues and opportunities. United Nations University working paper no. 24. http:// www.wiego.org/ occupational groups/

waste_collectors/Medina\%20Informal\%20Recycling\%20in\%20dvpg\%20countries.pdf. Accessed on 21 May 2010.

Medina, M. (2007). The world's scavengers: salvaging for sustainable consumption and production. Lanham: Altamira Press.

Rogerson, C. M. (1996). Urban poverty and the informal economy in South Africa's economic heartland. Environment and Urbanization. doi:10.1177/095624789600800115 1996 8: 167. 
Samson, M. (2010a). Reclaiming livelihoods: the role of reclaimers in municipal waste managementsystems.http:// www.groundwork.org.za/Publications/Reclaiming\%20Livelih oods.pdf. Accessed on 18 J une 2010.

Samson, M. (2010b). Reclaiming reusable and recyclable materials in Africa: a critical review of English language literature. http:// www.inclusivecities.org/research/RR6 Samson.pdf. Accessed on 18 J une 2010.

Schenck, C. J., \& Blaauw, P. F. (2010). Living on what others throw away: a preliminary exploration into the socio-economic circumstances of people collecting and selling recyclable waste. Paper presented at a feedback session on interesting research conducted in the inner-city and Sunnyside, Pretoria as part of UNISA's The Bright Site Project - 12 November 2010, UNISA Pretoria.

Theron, J. (2010). Options for organising waste pickers in South Africa. http:// www.wiego.org// publications/Organizing_Waste_Pickers_S_Africa.pdf. Accessed on 10 November 2010.

Webster, E. (2010). There shall be work and security: Utopian thinking or a necessary condition for development and social cohesion? Transformation: Critical Perspectives on Southern Africa, 72(73), 225-246. 